\title{
CENTER FOR SECURITY STUDIES AND CONFLICT RESEARCH
}

\begin{tabular}{|c|c|}
\hline Address: & $\begin{array}{l}\text { Center for Security Studies and Conflict Research } \\
\text { Seilergraben } 45-49 \\
\text { ETH-Zentrum/ SEI } \\
\text { CH - } 8092 \text { Zürich } \\
\text { Switzerland }\end{array}$ \\
\hline Director: & Prof. Dr. Kurt R. Spillmann \\
\hline Deputy Director: & Prof. Dr. Andreas Wenger \\
\hline Phone: & $(+411) 6324025$ \\
\hline Fax: & $(+411) 6321941$ \\
\hline E-mail: & postmaster@sipo.gess.ethz.ch \\
\hline Web address: & http://www.fsk.ethz.ch \\
\hline
\end{tabular}

$\mathrm{T}$ he Center for Security Studies and Conflict Research specializes in the field of national and international security studies and conflict analysis. Activities include research, teaching, and information services. The center has developed and maintains two major electronic information services - the International Relations and Security Network (ISN) and the Information Management System for Mine Action (IMSMA).

The center is the only one of its kind in German-speaking Switzerland and plays an important role as a complement to similar academic institutions in French-speaking Switzerland. It is part of an international network of scientific institutions and organizations and cooperates with numerous partners. The center's expertise has made it an important resource for public administrators and the media, and the center functions as a political consultant to the Swiss Federal Government.

\section{The Organization}

The center, which is located at the Swiss Federal Institute of Technology (ETH) in Zurich, was founded in 1986 by its current director, Professor Kurt R. Spillmann. Since 1997, Professor Spillmann has shared the responsibility of directing the center with Professor Andreas Wenger, deputy director. Due to steady growth in research activities and an increasing number of tasks and functions it undertakes, the center 
now has a staff of about 70 persons working in research, teaching, administration, the electronic information services, the reference library, and documentation. The library can be accessed by the public and contains 14000 books, 120 current periodicals and newspapers, and a document collection. The library is an important source of information in the fields of international relations, security policy, and conflict research.

In 1997 the Center for Security Studies and Conflict Research joined together with the chairs of international relations at the Swiss Federal Institute of Technology and the University of Zurich to form the Center for International Studies Zurich (CIS) (http://www.cis.ethz.ch). The CIS specializes in the fields of international relations, security studies, and conflict research.

\section{Research}

Research work at the center follows a broad, interdisciplinary approach appropriate to the real-world analysis of security policy and conflict management. Research is based upon an expanded conception of security that transcends traditional military conceptions to encompass political, economic, social, cultural, regional, and ecological aspects. Research is conducted by project teams, and members of the center pursuing individual projects. The projects are carried out in cooperation with international and national partners. The main foci of research are:

- Swiss security policy: Conceptual and practical issues of Swiss foreign and security policy;

- International security policy: Global security issues; security-related aspects of the foreign policy of nations; transatlantic relations and the architecture of European security;

- Conflict research: Basic research on the rise of violence and armed conflicts; the dynamics of conflicts; the theory and practice of constructive conflict resolution.

\section{Major Projects}

\section{Parallel History Project on NATO and the Warsaw Pact (PHP)}

In response to the declassification of NATO documents and the steadily growing availability of documents from the archives in Eastern and Central Europe, the Parallel History Project seeks to collect, analyze, and interpret these premier resources for the study of contemporary international history. As a cooperative undertaking of institutions and individuals dedicated to independent scholarly inquiry, the PHP brings together archivists, historians, and government officials. 
They locate, declassify, copy, translate, evaluate, and prepare for publication with commentaries documents from archives in Europe and North America.

The growing international network of PHP partners and associates benefits both the specialist academic community by providing new scholarly perspectives on the Cold War period and the wider public by multiplying the results of research in a readily accessible form. The findings are presented at conferences and published in print and multimedia volumes, as well as on the PHP's website http://www.isn.ethz.ch/php). Since its establishment in 1999, the project has collected thousands of pages of relevant material on the military aspects of the Cold War and published several online collections with revealing documents highlighting mutual threat perceptions and the "parallel" history of the Cold War alliances.

$$
\begin{array}{ll}
\rightarrow \text { URL: } & \text { http://www.isn.ethz.ch/php } \\
\rightarrow \text { Contact: } & \text { php@sipo.gess.ethz.ch }
\end{array}
$$

\section{Regionalization of Russian Foreign and Security Policy}

The objective of this international research project is to analyze regional dimensions of Russian foreign and security policy, an aspect of center-periphery relationship that has not yet been researched systematically. The aim of the project is to determine whether and how the central state understands the specific interests of Russian regions and to what extent regional processes have an impact on Russia's external relations and on integration processes within the CIS space and beyond.

A main task of this project consists in establishing profiles of selected Russian regions in order to examine their international security environment and relationship to the Moscow center. In order to present a true picture of Russia's uneven regional landscape, the regions have been carefully selected according to various criteria. Border regions and central regions, ethnic republics and oblasts and krais, poor agrarian regions and rich oil- and gas-producing regions are among the regions selected.

Apart from field research, several studies are planned to further elaborate on issues of a more general and/or theoretical character. Problems such as the regions' place in a globalizing world, the understanding of "sovereignty" from a regional point of view, the importance of external factors for Russia's regionalization, the impact of information and communications technology on center-periphery relations, and the role and political orientation of Russia's regional elite will, among others, be the issues included.

$\rightarrow$ URL:

http://www.isn.ethz.ch/russia/

$\rightarrow$ Contact:

perovic@sipo.gess.ethz.ch 


\section{Integrated Risk Analysis - Comprehensive Risk Analysis and Management Network (CRN)}

New or newly recognized vulnerabilities of modern societies and the rising complexity of causal circles involving various kinds of risks call for an intensified international dialogue and more co-operation in the field of national risk profiling - to be undertaken in an open structure, and not a hierarchical one. A new knowledge, a better understanding of new risks, their causes, interactions, probabilities and costs is needed. The "Comprehensive Risk Analysis and Management Network" (CRN) is a future-oriented initiative launched by Switzerland (Center for Security Studies and Conflict Research, ETH Zurich) and Sweden (ÖCB, The Agency for Civil Emergency Planning) to cope with the complexity and multidimensionality of the threats we are facing.

The risk analysis initiative is based on the Comprehensive Risk Analysis Switzerland Project, which was commissioned by the Swiss parliament and launched in 1991. In 1999, the project was transferred from the Central Office for General Defense to the Center for Security Studies and Conflict Research at the Swiss Federal Institute of Technology (ETH) in Zurich.

The purpose of the project "Integrated Risk Analysis" is to develop methodological expertise for the identification, evaluation and analysis of national collective risks that modern society in general, and Switzerland in particular, is facing. CRN was developed in order to support the dialogue between governmental and academic risk specialists and professionals in the areas of security risk analysis, assessment and profiling. As an electronic platform promoting the dialogue on risk profiling, the CRN site offers methodologies, procedures, tools and case studies for the security risk profiling process at the national, sub-national and local levels.

$\begin{array}{ll}\rightarrow \text { URL: } & \text { http://www.isn.ethz.ch/crn } \\ \rightarrow \text { Contact: } & \text { metzger@ @ipo.gess.ethz.ch }\end{array}$

\section{Electronic Services}

The center has developed and maintains two major electronic information servicesthe International Relations and Security Network (ISN) and the Information Management System for Mine Action (IMSMA).

\section{International Relations and Security Network (ISN)}

(http://www.isn.ethz.ch)

Parallel to the end of the Cold War and the breakdown of political barriers between East and West, the Internet has opened up new opportunities for interactive work 
across political and institutional borders. The new challenges presented by the information revolution demand knowledge, competence, and ethical awareness from the international security community. The International Relations and Security Network (ISN) is a unique instrument in these momentous times. Dozens of research institutes and international organizations, and hundreds of professionals working in the security community linked and supported by the ISN, create knowledge and facilitate information exchange, dialogue, and cooperation. They and the ISN are part of a vast network of cooperative relations that literally reaches around the globe. The ISN's services provide various open-source resources. While the ISN strives to foster an international, multidisciplinary dialogue, it also knows the importance of staying abreast of fast-paced developments in information technology. For and with its partners, the ISN produces new knowledge, creates dynamic forums, defines highquality standards, and continually improves its service offerings. The ISN is an essential component of Switzerland's participation in NATO's Partnership for Peace initiative and is the leading electronic information service for the fields of international relations and security policy.

\section{Information Services}

The ISN holds a leadership position in information technology (IT) for the international relations and security policy community. Its Internet-based services allow professionals to access, retrieve, and use information any time, anywhere. The ISN provides information solutions on the broadest range of IT services and content, customized to users' individual needs and interests. The ISN leverages Internet-based technologies designed to deliver user-centric information for efficient and responsive knowledge management in international security. The ISN is unique in its ability to provide this kind of package, both by itself and together with its extended networks of international partners.

\section{Limited Area Search Engine (ISN LASE)}

The ISN LASE is the most prestigious information service that the ISN provides to the international security community. The service enables users to access all available electronic documents in the fields of international relations and security from one site on the Internet. A high-quality index serves the sophisticated needs of professionals. Adopted as a tailored search interface by renowned institutions in the Partnership for Peace area, the ISN LASE provides an individualized and specialized service to partner organizations. The ISN LASE is a state-of-the-art search engine, designed by Eurospider, that supports text analysis and multilingual searches in several European languages, highlighting of matched terms, relevance feedback, and other advanced features. As a brand new feature, the ISN LASE offers a push functionality, which delivers information preconfigured according to a defined set of subscription criteria. Quality control of the ISN LASE content is guaranteed by its editorial board. 


\section{Links Library}

The ISN Links Library provides an outstanding collection of annotated links in the fields of international relations and security. As a searchable clearinghouse, the ISN Links Library provides a high-quality online reference directory of all relevant international organizations, governmental and non-governmental bodies, research institutes, journals, armed forces, and the full range of subject categories in international relations. Notable features include strong regional collections and extensive specialized holdings.

\section{Conference Calendar}

With its online Conference Calendar, the ISN provides an outstanding database of conferences in foreign affairs and security policy searchable according to 18 subject categories, all world regions, conference organizers, and country venues. The Conference Calendar demonstrates the ISN's commitment to delivering a high-quality public service to the international security community. The service is operated in cooperation with Columbia International Affairs Online (CIAO-Net).

\section{Facts in International Relations and Security Trends (FIRST)}

FIRST provides a sophisticated collection of statistics and data, including chronologies of conflicts and peacekeeping activities, arms transfers, military expenditures, and country profiles. Professionals will appreciate the authoritative and structured factual reference system of an integrated database supported by the world's leading research institutions in international relations and security policy. FIRST is run in cooperation with the Stockholm International Peace Research Institute (SIPRI) and other international partners.

\section{Security Watch}

In today's fast-moving and ever-changing security environment, professionals, researchers and the public at large need to know on a daily basis what is going on. They need to receive both global and national security news, reference and background information, and analyses in real time and on a continuing basis. The ISN addresses these pressing information needs through its Security Watch, an exclusively Internet-based news service focusing on the Partnership for Peace (PfP) region. Security Watch is unique in its coverage and scope in that it concentrates on security policy germane to the PfP community and is supplemented by links to background resources, documents, and further references.

\section{$\underline{\text { Research and Publications }}$}

The key to the ISN's success as a leading Internet-based network of electronic services is its close collaboration with its international partners. The quality and commitment of the ISN's partners is nowhere more evident than in the ISN Research 
and Publications section. Here the ISN provides for its users a range of high-quality documents in full text, including academic books and papers, regular journals and bulletins, and documentation to Partnership for Peace (PfP) activities. The Research and Publications section is used primarily by policy makers, academics, students, journalists, and other professionals in the fields of international relations and security who need up-to-date, relevant, and reliable information.

\section{Learning Material}

The ISN produces first-class e-learning environments in the fields of international relations and security studies. Our efforts aim at high-quality content, sound didactical approaches, and cutting-edge electronic environments. The target audience comprises students from the Swiss Federal Institute of Technology and teachers who use ISN products for their own educational needs. These products are available on CD-ROM or on the Internet; they are designed either as stand-alone programs for self-study or to support tutored online and residential courses.

\section{e-Learning}

The demand for educational services and the supply of educational programs and courses on the Internet is growing considerably. The ISN helps potential students to find appropriate distance-learning courses, produces its own multimedia educational programs, and provides support to its partners in designing and programming Internet courses. The ISN is also setting up an Advanced Distributed Learning (ADL) service within the Partnership for Peace Consortium of Defense Academies and Security Studies Institutes.

\section{Advanced Distributed Learning (ADL)}

Collaboration in the Partnership for Peace (PfP) transcends cooperative exercises. Education and training are key to the Extended and More Operative Partnership (EMOP). The PfP Consortium of Defense Academies and Security Studies Institutes, with its ADL working group, is the leading European promoter of an initiative that will bring web-based learning to all the PfP countries. Switzerland and the US have agreed to support this initiative with substantial resources. Eventually, the ADL working group will present a platform for the distribution of exchangeable web-based courses. It will also provide a set of courses from different nations that represent the core curriculum in security policy to every European civil servant and military officer.

\section{Vision}

Learning is becoming a life-long activity and is no longer restricted to specific locations like the classroom. The ADL working group is striving to build a common web-based platform for all European educational institutes in the field of security 
policy. This platform will allow for learning anywhere at any time. It will also enable institutes to:

- Distribute their courses over the web;

- Support the learning process with the most advanced web-based services;

- Put together their own courses, based on modules from different sources.

\section{Open Source Platform}

Key to the special environment of the PfP Consortium is a solution that keeps infrastructure and systems costs for partners down and at the same time draws on available high-skill labor in Central and Eastern Europe. A so-called "open source" solution provides an optimal basis for such a process. At the core of the solution is the PfP Learning Management System, or PfP-LMS, which is being developed on behalf of and within the context of the ADL working group. Interested parties can use and expand the core system at no charge under the condition that, in return, all developments to the system are made available at no cost.

\section{Content}

The leading partners in the ADL working group maintain a cooperative development team (CDT) to help partners convert their content into an online format. The CDT focuses on didactic support and technical services to convert existing courses into well-structured and comprehensible multimedia online courses. The CDT is happy to assist any interested parties with their course conversions.

\section{The Information Management System for Mine Action (IMSMA)}

(http://www.imsma.ethz.ch)

IMSMA is an information management system that improves capabilities for decision-making, coordination, and information policy related to humanitarian demining (Mine action). Since January 1999, IMSMA has been the UN-approved standard for information systems supporting humanitarian de-mining. Collection of standardized data in a comprehensive information system improves data evaluation using powerful statistical and geographical tools.

Set-up as a networked multi-user system, IMSMA enables several users to enter and evaluate their data simultaneously. The system consists of two modules, since information management capability in Mine action is needed at two different levels: Data is collected and evaluated in mine-affected countries at Mine Action Centers (MACs) and entered into the IMSMA Field Module. Using this system, countries possess improved capabilities for coordinating, prioritizing, and executing de-mining activities. 
In addition to local data management capabilities, information can be transferred in the future to the IMSMA Global Module (GM) where consolidation and analysis will be performed. Results of this process can be used at a regional and global level to support strategic decision-making and provide information for the general public on the scale of the mine problem and the progress of mine action activities over the Internet. Mine action centers will be able to directly profit from the Global Module technology with the GM Country Edition that brings dynamic mapping and explorative statistical analysis to their website and improves the countries information dissemination possibilities.

The Geneva International Centre for Humanitarian Demining is providing the IMSMA Field Module free of charge to the mine action community. Using IMSMA as the UN (as well as the de-facto) standard in mine action enables for the first time to collect and evaluate data in a standardized form. This supports a better and more comprehensive capability of data evaluation on a national, multinational as well as multi organizational level.

Analyzing the requirements of the international Mine community demonstrated the need for Information Management capabilities at two different levels. Country and regional mine action centers require a powerful system for gathering and evaluating data at country and regional levels, while at the international level a decision support system, as well as a system that provides information to the general public is needed. IMSMA takes these requirements into account with the development of two independent but inter-linked systems: the Field Module and the Global Module.

\section{The Field Module}

Development of the IMSMA Field Module began in fall 1998. While the first release of the Field Module concentrated on covering the urgent need for providing humanitarian demining operations with IT support, the current version and future development is designed to provide information management and operational support to all aspects of mine action.

The Field Module was defined and developed for use at country Mine action Center (MAC) and regional center levels. To fulfill the specific requirements of coordinating and performing Mine action activities, the United Nations developed and approved new international standards for humanitarian demining. The IMSMA Field Module was used as reference system for defining the new standards and is the only system available that complies with these standards. The IMSMA Field Module is the UN standard for Information Management at Mine action Centers.

The Field Module allows the Mine action Center to record, evaluate and visualize information. Considerable effort has gone into developing a comprehensive but easy 
to use system. Colors, pictures, tool-tips and graphic- as well as menu-driven system navigation support the user. In addition, the Field Module is fully multilingual and can be translated by the user.

\section{Global Module}

The IMSMA Global Module (GM) was initiated and is under development to address the need for data aggregation at national, regional and global level. For the first time in the history of mine action, the IMSMA Global Module will provide the possibility for systematic data consolidation, aggregation, and analysis using a comprehensive data warehouse solution. This process aims to support strategic decision-making for the United Nations and other interested parties and to provide information on the scale of the mine problem and the progress of mine action activities to the general public over the Internet.

Development of cutting-edge technology by the Center for Security Studies and Conflict Research permits the IMSMA Global Module to provide dynamic mapping capabilities as well as exploratory statistical analysis tools (Online Analytical Processing or OLAP) over the Internet directly to the desktop of its users. It also provides a comprehensive view of multiple aspects of Mine action by providing an extensive link library to relevant information that exists on the Internet.

As part of the Global Module, a data warehouse to support strategic decision-making is being developed in order to achieve the important goal of providing relevant information on the mine situation and on the progress in mine action to the user. In order to provide dynamic mapping and exploratory statistics to the users, the development of GIS and statistical reporting mechanisms has been undertaken. These mechanisms use the same base data originating from IMSMA Field Modules, other operational databases, UN databases, or other information sources. The user accesses the GIS as well as the statistical tools over the Internet by accessing the central webserver of the IMSMA Global Module. The exploratory analysis capability with online GIS tools was awarded ESRI's prestigious "Special Achievement in GIS" award in 2001. 


\section{ADVANCED INFORMATION AND COMMUNICATIONS TECHNOLOGIES IN SUB-REGIONAL SECURITY COOPERATION}

$\mathrm{M}$ odern information and communications technologies have considerable, and as yet - largely underutilized, potential to contribute to security cooperation. This short paper provides an introductory presentation of a project, aimed at utilization of technology, including Internet and Web technologies, to enhance effectiveness and efficiency of security cooperation in South East Europe (SEE). More complete presentation of the project will be published in one of the coming issues of "Information \& Security." Updates will be available trough Internet at www.GCMarshall.bg.

The project is entitled "Cooperative C4 Systems Development in South East Europe: From Coordination to Joint Procurement." It builds on the encouraging developments in the Balkans and the demonstrated willingness of SEE countries to cooperate in conflict prevention and crisis management and to take responsibility for security and stability in their own home.

The overarching concept is that SEE countries need to develop and maintain, in cooperation, common crisis management capacity. The challenge is to build and sustain cooperative crisis response capabilities while efficiently using limited financial resources.

The project is intended to devise feasible regional strategies for evolutionary $\mathrm{C} 4$ systems development in support of cooperative crisis management and other regional security initiatives. Among expected results are policies for coordinated, and in the future - joint, procurement of technologies and systems for information collection, situational awareness, distributed decision making, communications, command and control in managing multinational multi-agency crisis prevention and response. We shall cover potential regional actions to crises of political-military nature, natural disasters, industrial accidents, and humanitarian crises, as well as organizational and technology solutions to combat arms proliferation, illegal trafficking of people, drugs and goods, money laundering, and terrorism. Of particular interest will be the areas requiring advanced technology implementation in close civil-military cooperation, 
such as emergency management, aerospace management, control of maritime and river traffic, and coastal zone management.

To achieve this goal the research team will pursue the following objectives:

1. Create a data bank of existing $\mathrm{C} 4$ systems, C4 development proposals, initiatives, and projects in SEE and overlapping regions.

2. Create a system model of cooperative security arrangements in SEE, accounting for existing consultations mechanisms, organizational/ command arrangements, crisis management capabilities (military forces, paramilitary formations and civil organizations), and implemented, or potentially implemented, technology.

3. Devise and test, through simulations, a flexible and efficient operational architecture, system and technical architecture, as well as a blueprint of a notional "desired end state" to serve as benchmark.

4. Propose principles, procedures and system for coordinated/joint acquisition of $\mathrm{C} 4$ systems.

5. Devise a resource constraint strategy for cooperative $\mathrm{C} 4$ development and coordinated/joint procurement.

\section{Points Of Contact:}

Dr. Todor Tagarev

Director Programs, Center for

National Security and Defense

Research

Bulgarian Academy of Sciences

1, "15 November" Str.

Sofia 1040, Bulgaria

Tel.: +359 87244810

E-mail: Tagarev@space.bas.bg http://www.icsr.bas.bg/cnsr
Dr. Velizar Shalamanov

Chairman

"George C. Marshall - Bulgaria"

3, Sheinovo Str., et. 6

Sofia 1504

Bulgaria

Tel.: +359 87954770

E-mail: Shalamanov@GCMarshall.bg http://www.GCMarshall.bg 